\title{
LA INFORMACIÓN COMO SERVICIO PÚBLICO EN LOS MEDIOS DE COMUNICACIÓN
}

Carmen Marta-Lazo: Universidad de Zaragoza (España)

José Antonio Gabelas Barroso: Universidad de Zaragoza (España)

Alejandro Silva Faci: Universidad de Zaragoza (España)

\section{Introducción}

La primera aparición de la expresión libertad de prensa, denominada "libertad de palabra" aparece en la obra "El paraíso perdido" de John Milton (1667). En el ámbito legislativo, la primera vez que se incluye esta libertad es en la Declaración de Derechos de Virginia, en 1776: "La libertad de prensa es uno de los grandes baluartes de la libertad y no puede ser restringido sino por un gobierno despótico".

El artículo 11 de la Declaración de Derechos del Hombre y del Ciudadano, en 1789, matiza posibles limitaciones por otros derechos: "La libre circulación de pensamientos y opiniones es uno de los derechos más preciosos del hombre. Todo ciudadano puede hablar, escribir e imprimir libremente con la salvedad de responder del abuso de esta libertad en los casos indicados por la ley".

La consagración jurídica definitiva de la libertad de prensa se produce en 1791, se protege constitucionalmente en la Primera Enmienda de la Constitución de los Estados Unidos, en la que se contempla que: "El Congreso no podrá aprobar ley alguna que coarte la libertad de palabra e imprenta".

En España, el primer reconocimiento de la libertad de expresión se recoge en la Constitución de las Cortes de Cádiz de 1812: "Todos los españoles tienen libertad de escribir, imprimir y publicar sus ideas políticas sin necesidad de licencia, revisión y aprobación alguna anterior a la publicación, bajo las restricciones y responsabilidad que establezcan las leyes".

La Asamblea General de las Naciones Unidas promulga en 1948 la Declaración Universal de los Derechos Humanos, que establece un marco internacional para el reconocimiento de los derechos y libertades. El tema que nos ocupa se circunscribe al artículo 19: "Todo individuo tiene derecho a la libertad de opinión y de expresión; este derecho incluye el de no ser molestado a causa de sus opiniones, el de investigar y recibir informaciones y opiniones, y el de difundirlas, sin limitación de fronteras, por cualquier medio de expresión".

En la primera parte del artículo, se enuncia en quien recae la titularidad de la información: en "todo individuo". Por tanto, se trata de un derecho universal, perteneciente a todos los ciudadanos, al público en general. En la segunda parte del

Recibido: 01/03/2007---Aceptado: 16/04/2007---Publicado: 12/11/2007 


\section{LA INFORMACIÓN COMO SERVICIO PÚBLICO EN LOS MEDIOS DE COMUNICACIÓN}

artículo, constan las funciones relativas a la libertad de opinión y expresión, que se enmarcan en torno a tres ejes: investigar, recibir informaciones y opiniones, y difundirlas. Estos cometidos se corresponden con las tres facultades tradicionales del periodismo: investigar, difundir y recibir información.

Como consecuencia de las limitaciones prácticas que tienen los ciudadanos para ejercer las funciones "investigar y difundir", la sociedad delega, de manera tácita, en los periodistas y, por extensión, en las empresas periodísticas, estas realizaciones. Son, pues, los medios de comunicación colectiva o "de masas", como mediadores, en quienes recaen estas labores, con la exigencia de hacer frente a la veracidad, como cualidad de partida de la información, bien contrastada y asumida como tal.

La tercera finalidad, el hecho de "recibir información", es validada en el proceso comunicativo desde el enfoque del receptor, como destinatario de los mensajes que emiten los medios.

Como cierre del artículo 19, se refleja la universalidad de medios para ejercer el derecho a la libertad de expresión y de opinión: "sin limitación de fronteras, por cualquier medio de expresión". De este modo, podemos concluir que se anticipa a la idea de mundo interconectado o "aldea global" propuesta por Mc Luhan (1969).

En la Constitución española de 1978, se regula en el artículo 20, el derecho a la libertad de expresión. En él, se incluyen cinco epígrafes, que contienen la protección de los derechos, garantías y limitaciones.

El primero establece el contenido de esta libertad: "expresar y difundir libremente los pensamientos, ideas y opiniones mediante la palabra, el escrito o cualquier otro medio de reproducción" (apdo. a) y "a comunicar o recibir libremente información veraz por cualquier medio de difusión" (apdo. d). También se incluyen los derechos: “.... la producción y creación literaria, artística, científica y técnica" y "a la libertad de cátedra" (apdos. b y c). Asimismo, se consideran dos garantías en el ejercicio de estas libertades: la cláusula de conciencia y el secreto profesional.

El segundo epígrafe imposibilita la censura previa, aunque en el cuarto se haga referencia a los límites a la libertad de expresión: el derecho al honor, a la intimidad, a la propia imagen y a la protección de la juventud y la infancia, junto con los que se establezcan en los preceptos de las leyes que lo desarrollen.

El tercero establece que la ley regulará la organización y el control parlamentario de los medios de comunicación social dependientes del Estado o de cualquier ente público. Además, incorpora las garantías para el acceso de todos los grupos sociales y políticos, respetando el pluralismo de la sociedad y de las diversas lenguas de España. 
El último apartado del artículo ordena la resolución judicial como única vía para el secuestro de publicaciones, grabaciones y otros medios de información.

\section{Metodología}

Esta investigación es de carácter exploratorio y tiene como objetivos:

- Revisar la literatura existente relacionada con el tema de la libertad de expresión en los medios de comunicación tradicionales

- Analizar la proyección del pluralismo informativo en las redes sociales.

- Reflexionar acerca de la importancia de la intervención del sistema educativo como escenario para fomentar la participación ciudadana desde un modelo educomunicativo en el que se potencien los nuevos entornos digitales como medios para aprender e intercambiar información de manera activa.

Partimos de que la información es un instrumento en poder de la sociedad. La información es un derecho que no debe pertenecer al poder político ni a los empresarios, sino a la ciudadanía. El necesario pluralismo en un país democrático es el valor que asegura a los ciudadanos la diversidad informativa.

Existen dos formas de medir la diversidad informativa:

- en el plano cuantitativo: la cantidad de medios de comunicación que existen en el mercado.

- en el plano cualitativo: los modelos de control y dependencia de los medios. Es decir, la respuesta a la pregunta: ¿quiénes son los dueños de la información?

Más medios no significa más pluralidad de voces. La libre competencia puede asegurar diferentes fuentes de expresión pero no la variedad de expresiones, ideas e informaciones que se transmiten a la sociedad. El pluralismo no se consigue con la diversidad de empresas o la diversificación de las entidades que las controlen. Lo que determina el pluralismo es el contenido editorial de los medios y no la pluralidad de empresas. Sírvanos como ejemplo que, si bien el nacimiento de la TDT podría haber supuesto un enriquecimiento de medios, la concentración en manos de los mismos operadores de la televisión generalista, impidió un crecimiento en este sentido.

Como estima Murciano (2005: 27), "La concentración pone al ciudadano común en una situación marginal con respecto a derechos fundamentales como son los de la libertad de expresión, el acceso a la información, la diversidad de las fuentes de información y la diversidad cultural".

Como consiguiente, se observa una tendencia en los mass media a la homogeneización de contenidos y formatos, siendo pocas las experimentaciones 0 


\section{LA INFORMACIÓN COMO SERVICIO PÚBLICO EN LOS MEDIOS DE COMUNICACIÓN}

innovaciones hacia la búsqueda de modelos alternativos que apuesten por un cambio. En el plano de los contenidos, en los informativos, sólo basta con realizar un análisis de los temas abordados y presentados en los sumarios, independientemente de la cadena de emisión, suelen ser comunes, debido a la misma proveniencia de las mismas fuentes, las grandes agencias informativas.

Una estrategia que refleja de modo claro esta homogeneización es la creación o subrayado de estereotipos y representaciones que simplifican y cargan la realidad de connotaciones ideológicas. Como indica Spectus (2004: 106), "¿Qué imagen transmite el Norte del Sur? Dos géneros televisivos responden a esta pregunta: los informativos y la publicidad. El llamado Tercer Mundo (obsérvese la carga semántica del término), es el lugar de las desgracias, bien originadas por causas naturales 0 artificiales, como guerras o desórdenes. El Sur es la miseria y la inseguridad, pero también el descanso exótico para el ciudadano desarrollado del Norte".

Los poderes públicos han de tomar medidas para asegurar el pluralismo. Su intervención a la hora de permitir la creación de nuevos medios de comunicación o del reparto de licencias tiene que ser equilibrada. Si el control de los medios es proporcionado, se supone que las informaciones transmitidas también lo serán.

La prensa constituye, según Émile Dovifat (1959-1960: 3 y ss.), un "órgano de la democracia", siendo parte responsable de su florecimiento y decadencia. La información, es entendida por este autor como un instrumento que permite al hombre formarse juicios sobre lo que le rodea, conocer el entorno. Este conocimiento de la realidad se traduce en una mejor capacidad de elegir. Una prensa libre, es por tanto, un componente esencial de la democracia, en la medida en que garantiza la pluralidad y la libertad. De manera contraria, los medios pueden contribuir a la decadencia o enfermedad del sistema democrático si no consideran el servicio al ciudadano como su insignia. Bajo esta consideración y con un planteamiento apocalíptico Chomsky (1997: 16) señala que "la propaganda es a la democracia lo que la cachiporra al estado totalitario... dado que, de nuevo, los intereses públicos escapan a la capacidad de comprensión del rebaño desconcertado".

El nivel donde se debe medir la manifestación real del pluralismo es en la audiencia, en el público, en la sociedad, en el receptor. Esta es la verdadera referencia para comprobar la salud del sistema democrático. Hay que preguntarse si se da respuesta informativa a todos los ciudadanos y desde todos los posibles ángulos para que desarrollen sus propias interpretaciones respecto a los hechos acontecidos. 
Por un lado, lo que determina el pluralismo son los contenidos, la variedad de informaciones, opiniones y modelos de vida que reflejan los medios de comunicación. Por otra parte, el pluralismo también tiene que ser garantía del derecho de todos los ciudadanos a participar en los contenidos, mediante una constante retroalimentación que garantice la respuesta abierta a los contenidos que ofrecen los medios. Mediante el "modelo horizontal" que propone Freire (1969), lejos de un referente "bancario" o "falsamente democrático", los ciudadanos tienen derecho a expresar de manera activa y directa sus opiniones en los medios. Este es el auténtico pluralismo social, en el que todos se encuentren representados, no sólo como receptores de información, sino también como emisores en sentido pleno.

La interactividad real pasa por una vía de feed-back continua, mediante la inclusión de las propuestas, demandas y necesidades de colectivos ciudadanos, en general, y reflejo de la expresión de cada uno de nosotros como miembros del sistema, en particular. La persona que interviene en este proceso bidireccional fue nominada por Cloutier (1975) como "EMIREC", acrónimo formado por las tres primeras letras de los términos emisor y receptor. En el estadio que este autor llama "periodo de la comunicación individual", "en lugar de receptores pasivos hablaremos de individuos que se van a informar al mismo tiempo que van a informar a otros" (Aparici y García Matilla, 1987: 17). Los EMIRECs actúan alternativamente en las dos funciones dentro del proceso dialógico de comunicación.

De este modo, señala Gabelas (2005: 75) que "se precisa la promoción de medios horizontales gestionados por el tejido asociativo y ciudadano. Asistimos a un encubierto monopolio de los medios de comunicación. La ciudadanía necesita recuperar su derecho a la expresión y a una información digna y plural. Son necesarias plataforma que permitan la comunicación y la interacción".

Es el momento de preguntarnos si la aparición de nuevos medios surgidos de la amplia cobertura nuevo-tecnológica implica o no que los ciudadanos tengan nuevas posibilidades expresivas.

Si bien, la mezcla de las nuevas tecnologías y los medios de comunicación clásicos han generado un modelo de prensa en que la información es inmediata y muy abundante, se producen algunos límites a la pluralidad informativa.

El jurista Desantes Guanter (2004) califica de "infopolución" la contaminación informativa que impide al sujeto filtrar con criterio propio la recepción de información. Desde similar perspectiva, Ramonet (1998: 25) apunta la imposibilidad de conseguir información pura a través de la pantalla televisiva: "Muchos ciudadanos estiman que... mirando en la pequeña pantalla pueden informarse con seriedad. Error mayúsculo. Por tres razones: la primera, porque el periodismo televisivo, estructurado como una ficción, no está hecho para informar sino para entretener; en 


\section{LA INFORMACIÓN COMO SERVICIO PÚBLICO EN LOS MEDIOS DE COMUNICACIÓN}

segundo lugar, porque la sucesión rápida de noticias breves y fragmentadas produce un doble efecto negativo de sobreinformación y desinformación; y finalmente, porque querer informarse sin esfuerzo es una ilusión más acorde con el mito publicitario que con la movilización cívica".

Por su parte, el sociólogo Castells (1999) establece una triple tipología de ciudadanos atendiendo a su relación informativa con los medios: "los desinformados, que sólo tienen imágenes; los sobreinformados, que viven en el torbellino; y los informados, que seleccionan, ordenan y pueden pagar la información".

\section{Resultados}

La delegación de la libertad de expresión del ciudadano en los medios por motivos de logística forma parte de los modos de producción de los llamados medios tradicionales o "mass media". Pero los nuevos medios pueden suponer una forma de recuperar el derecho individual a la información, por la accesibilidad y facilidad de uso por parte de todos. Sírvanos como ejemplo las webblogs, los SMS (mensajes que podrían corresponderse con el lead de la información), correos electrónicos, radios barriales o pequeños periódicos de difusión vecinal.

Las frecuencias por las que se emite la radio en España son propiedad del Estado que las cede en régimen de concesión por un periodo determinado, pero renovable, a través del Ministerio de Industria (organismo del que depende esta materia en la actualidad). En la actualidad, las diferentes leyes reconocen la posibilidad de explotar la radiodifusión a instituciones (estatal, autonómica y local) y a empresas privadas, pero no contemplan la existencia de otras emisoras, entre las que encontraríamos "las culturales sin ánimo de lucro". Por ese motivo, las emisoras de carácter reducido en cuanto a su eje de emisión están actualmente en una situación de alegalidad.

Todos estos medios tienen como valor añadido que se completa el proceso de comunicación a través de la retroalimentación, ya que se permite dar una respuesta bidireccional entre emisor y receptor. Esta posibilidad de participación queda limitada en los medios tradicionales a esos formatos que permiten el retorno y no siempre una respuesta en sentido pleno (cartas al director, llamadas oyentes, banners de SMS, etc.). Es interesante que nos planteemos la siguiente cuestión: ¿cuántos de los mensajes quedan en el camino sin llegar a ser publicados o emitidos?...

Por consiguiente, la democratización de la información viene dada a través del surgimiento de medios independientes y de soportes alternativos que permiten la interacción entre los emisores y receptores. A veces, incluso, se convierten en fuente de los medios tradicionales. Por ejemplo, las webs que por criterios de selección informativa son noticia. 
Por otro lado, desde los grandes medios no hay que olvidar su finalidad de ser un servicio público, con sus consiguientes derivaciones "servicio del público y para el público". Pero, ¿dónde empieza y dónde acaba el "servicio público esencial" al que tienen que hacer frente los medios de comunicación. Esta cláusula se contempla en las propias leyes, tanto de televisión pública como privada de nuestro país. En la Ley 4/1980 del Estatuto de la Radio y la Televisión, se hace referencia expresa a la actividad de los medios de comunicación social del Estado, se inspirará, entre otros principios, en que las programaciones de RTVE deberán “...propiciar el acceso de todos a los distintos géneros de programación y a los eventos institucionales, sociales, culturales y deportivos, dirigiéndose a todos los segmentos de audiencia, edades y grupos sociales..." (artículo 5). Este marco se hace extensible posteriormente a las cadenas y canales privados, ya que en el artículo $3^{\circ}$ de la Ley 10/1988, de Televisión Privada, se contempla que la gestión indirecta (del servicio público esencial de la televisión), por parte de las Sociedades concesionarias, se inspirará en los mismos principios de la Ley 4/1980.

Como diagnóstico de los contenidos culturales ofrecidos por el medio televisivo, Rodríguez Pastoriza (2003: 41) señala que “...El concepto mercantilista de empresa televisiva colisiona con la función social y cultural de los contenidos de su programación. Los métodos de financiación de las televisiones y su competencia agresiva las fuerzan a vigilar milimétricamente los ratings de audiencia y a dejar en manos de la tiranía del consumidor los criterios de calidad de sus productos. Pero que las audiencias de los programas culturales sean minoritarias no significa que esta programación no sea rentable. Podrá no serlo en términos económicos (...), pero nunca en términos sociales y de servicio público...".

"La responsabilidad de las cadenas de televisión ante el ciudadano en global y, los menores en particular, debería fundamentarse en la atribución del 'servicio público esencial', como uno de los principales ejes respecto al cual se deben guiar los programadores de las distintas televisiones, tanto de las pertenecientes a entidades públicas como las de operadores privados. Además de la función de servir como entretenimiento que está prevaleciendo en la actualidad, deberían considerar en mayor medida la finalidad informativa y formativa, atendiendo a los intereses de la audiencia. De hecho, los propios niños demandan más programas educativos y manifiestan, de forma abierta, que una de las utilidades que para ellos tiene ver la televisión es la de aprender", como pudimos concluir en una investigación llevada a cabo en la Comunidad de Madrid (Marta-Lazo, 2005a: 30-31).

Buckingham (2005: 241-242) expone un doble enfoque de la educación en medios: "dialógico" y "dinámico". La alfabetización mediática implica y exige un diálogo continuo entre lo que saben y conocen los niños y jóvenes de los medios, entre su experiencia y el conocimiento que los profesores y educadores podemos ofrecer. Con frecuencia planteamos dinámicas, ejercicios, actividades que sólo pretenden 


\section{LA INFORMACIÓN COMO SERVICIO PÚBLICO EN LOS MEDIOS DE COMUNICACIÓN}

afirmar nuestras ideas iniciales. Muy corriente es programar una determinada producción mediática (realizar una revista o periódico escolar, un determinado corto o grabación, la portada para una revista o una fotonovela...) y pasarles al final un cuestionario/evaluación con el que se pretende que nuestros conceptos iniciales se vean confirmados. Desde el enfoque dialógico se busca conversar con los estudiantes, de modo que el proceso vivido con la experiencia que tienen, se convierta en una reflexión abierta sobre lo que han hecho, sus experiencias y las posibilidades de tener otras diferentes. Con este planteamiento, se asume que el conocimiento del profesor también se somete a análisis.

Lo dialógico se completa con lo dinámico. El proceso de trabajo empuja hacia delante y vuelve hacia atrás, conjuntando los aprendizajes. Acción y reflexión forman una goma elástica que se estira y encoge desde y con la participación de todos. Los jóvenes, como consumidores críticos, activos y autónomos construyen su propio itinerario de búsqueda y exploración deslizándose por el análisis de los mensajes mediáticos y creando sus propias producciones. El trabajo en grupo, la socialización que procura, el placer y la satisfacción de ver su producción de inmediato son ingredientes básicos en el aprendizaje.

Volvamos al papel de los medios de comunicación de masas. Una educación para la comunicación, por ende, para la participación no puede estar de espaldas a la existencia de las pantallas y la convivencia con las mismas. El impacto mediático que no educa, deseduca. El consumo de televisión, Internet, videojuegos, móviles, cine, publicidad, moda... se hace fuera de la escuela, y en gran parte fuera de la familia, pero escuela y familia tienen todavía una asignatura pendiente: convertirse en escenario de reflexión, diálogo, interacción sobre estos consumos. Escenarios que pueden provocar y generar la contemplación de otros valores diferentes a los impuestos por el ambiente.

Como apunta Marta-Lazo (2006: 211-212), "Los padres, por encontrarse en el contexto inmediato en el que se desarrolla la interacción con el medio televisivo, son una de las principales fuentes de información en la 'lectura de imágenes' (...) La compañía de los padres durante el proceso de visionado es de gran ayuda para ofrecer orientaciones relacionadas con los posibles valores negativos 0 'contravalores' que se desprenden de determinados mensajes y que los niños no siempre alcanzan a ver. A raíz de los filtros que los adultos les proporcionen y de la contextualización de aquello que no lleguen a entender, los pequeños activarán mecanismos de defensa para encender una 'luz' en futuras aproximaciones al medio en las que puedan realizar un consumo en solitario e irán adquiriendo experiencia para realizar una 'lectura crítica' de los mensajes".

Hace años que se celebra en diferentes foros y lugares, un debate en torno en torno a la educación formal y no formal. Sobre cómo los aprendizajes son a lo largo de toda la vida, en torno a la participación de los padres, el aprendizaje a distancia, la formación en casa, y sobre todo, la vital importancia del tiempo libre.

Los medios educan en todo momento, de modo más placentero y lúdico que la escuela. Por lo tanto, la educación en medios no debiera quedar recluida en la 
escuela (aunque ya quisiéramos que la escuela asumiera bastante más esta posibilidad). Una alfabetización mediática precisa un trabajo en red, donde sus educadores estén asociados con organizaciones que operan fuera de los espacios formales de educación. No se puede concebir una pedagogía de la participación si no se diseñan puentes entre la escuela y la comunidad que la enmarca (familia, barrio, asociaciones).

Lo dicho exige dejar de ser multitud, gente "unida" por una emoción, producida por una tragedia concreta; dejar de ser masa "unida" por un foco de atención común, partido de fútbol, para empezar a ser público en el pleno sentido del término. O sea, conjunto de personas vinculadas por la discrepancia y el diálogo racional. No por una emoción o hecho puntual. Como público bien podemos reivindicar nuestro derecho a una información veraz y contrastada. El derecho a una libertad de expresión, no sólo de los grandes medios (que tampoco existe), también de los pequeños, y de cada ciudadano. Pero está claro que esto nadie lo regala.

La sociedad civil precisa una vertebración para articular plataformas concretas que reclamen y exijan estos derechos. Los distintos colectivos implicados en la información (periodistas, comunicadores, educadores, profesores, padres y madres, agentes sociales) pueden crear cauces de expresión y asociación. Aunque pueda parecer que éstos no existen, podemos decir que entre los educadores del estado español existen varios grupos como Aire, Comunicar, Spectus, etc. que llevan décadas trabajando.

La educación para la democracia, para la participación obliga desde la escuela a revisar los roles del profesorado, que dejan de ser transmisores para convertirse en facilitadotes de aprendizaje. Obliga desde la familia a un trabajo en red con sus hijos, los medios, las instancias educativas (Marta-Lazo, 2005b; 1999; 1997). Obliga a la sociedad civil a la creación de plataformas que reclamen y exigen el derecho a estar bien informado. A tener una televisión pública digna, que entretenga educando en los valores democráticos. Obliga a los estamentos políticos a una verdadera autorregulación de los medios, con la creación definitiva del Consejo Superior Audiovisual (no podemos olvidar que el estado español es el único europeo que carece del mismo). En fin, obliga al estado a una distribución racional de recursos para poner en marcha una política educativa y sanitaria que también sea comunicativa.

\section{Conclusiones y discusion}

Los medios de comunicación tienen como finalidad atender al "servicio público esencial" que se contempla en el marco legislativo de su razón de existir. Es una realidad los límites de participación real que la ciudadanía tiene en los mass media. 


\section{LA INFORMACIÓN COMO SERVICIO PÚBLICO EN LOS MEDIOS DE COMUNICACIÓN}

Los nuevos medios surgidos fruto del desarrollo tecnológico suponen una apuesta como foros de información ciudadana.

No hay que olvidar que el proceso comunicativo no queda finalizado sin la posibilidad de la retroalimentación por la audiencia. Por ello, tanto los medios tradicionales como los nuevos deben contemplar espacios en los que se escuche la voz de todos.

La escuela es una importante plataforma para educar en modelos dialógicos y preparar en un aprendizaje para la ciudadanía, centrado en la libertad de expresión, en la participación y en los valores democráticos con un sustrato cívico como referente.

\section{Referencias bibliográficas}

APARICI, R. Y GARCÍA MATILLA, A. (1987). Imagen, vídeo y educación. Madrid: Fondo de Cultura Económica, colección Paideia.

BUCKINGHAM, D. (1987). Educación en medios. Barcelona: Paidós.

CASTELLS, M. (1999). La era de la información: economía, sociedad y cultura. Madrid: Alianza.

CHOMSKY, N. (1997). Cómo nos venden la moto. Barcelona: Ediciones Icaria.

CLOUTIER, J. (1975). L'ère d'EMEREC (ou la communication audio-scripto-visuelle à l'heure des self-média). Canadá: Les Presses de l' Université de Montreal.

DESANTES GUANTER, J. M. (2004). Derecho a la información. Materiales para un sistema de la comunicación. Valencia: Fundación COSO.

DOVIFAT, E. (1959). Periodismo, 2 vols. Tomo I, Uteha.

FREIRE, P. (1969). La educación como práctica de la libertad. Montevideo: Tierra Nueva.

GABELAS J.A. (2005). El universo ubicuo, en Pantallas Sanas. Programa Cine y Salud. Zaragoza: Gobierno de Aragón, p. 61-76.

GARCÍA MATILLA, A. (2003). Una televisión para la educación. La utopía posible. Barcelona: Gedisa.

GRUPO SPECTUS. (2004). Máscaras y espejismos. Una aproximación al impacto mediático. Del análisis a la acción. Madrid: Ediciones de la Torre.

KAPLÚN, M. (1998). Una pedagogía de la comunicación. Madrid: Ediciones de la Torre. 
McLUHAN, M. (1969). La galaxia Gutenberg: Génesis del homo typographicus. Madrid: Aguilar.

MARTA-LAZO, C. y DE ÁNGEL GARCíA, N. (1997). Niños y televisión: de los estudios sobre los efectos a los de recepción activa, en Revista de Ciencias de la Información.

MARTA-LAZO, C. (1999). Contextos socializadores que influyen en la recepción televisiva infantil, en Revista de Ciencias de la Información.

MARTA-LAZO, C. (2005a). Agentes mediadores y responsables del consumo infantil de televisión: familia, escuela y medios de comunicación, en Comunicación y Hombre: revista interdisciplinar de ciencias de la comunicación y humanidades, p. 19-34.

MARTA-LAZO, C. (2005b). La televisión en la mirada de los niños. Madrid: Fragua.

MARTA-LAZO, C. (2006). La guía paterna en el consumo televisivo: un modelo cuantitativo y cualitativo en el aprendizaje de contenido, en Revista Ámbitos, $n^{\circ}$ 15 , p. 211-221.

MURCIANO, M. (2005). Nuevos conglomerados mediáticos y libertad de expresión: grupos de comunicación, democracia y política de comunicación, en Revista Comunicación, Democracia y Ciudadanía.

RAMONET, I. (1998). La tiranía de la comunicación. Madrid: Temas de debate.

REIG, R. (2002). La comunicación en su contexto. Una visión crítica desde el periodismo. Sevilla: Centro Andaluz del Libro.

RODRÍGUEZ PASTORIZA, F. (2003). Cultura y televisión. Una relación de conflicto. Barcelona: Gedisa.

VERDÚ, V. (2003). El estilo del mundo. Barcelona: Anagrama. 